\title{
PENDIDIKAN ISLAMIC PARENTING DALAM HADITH PERINTAH SALAT
}

\author{
M. Burhanuddin Ubaidillah \\ STAI Darussalam Krempyang Nganjuk \\ Email: burhanudinubaidillah24@gmail.com
}

\begin{abstract}
Hadith prayer orders textually understood at first glance seem to highlight physical violence that is not relevant to modern education. Textual and contextual understanding of Hadith must distinguish between fixed goals and changing means so that new interpretations of Hadith can be found. The purpose of this study is to explain the concept of Islamic Parenting education in the hadith about prayer orders. The method used is a library review by examining the study of the books and the thoughts of the scholars. Based on Islamic Parenting education can be traced the main spirit that the Prophet's education in practice was actually gentle and proved to have a profound influence on the souls of his friends. Islamic Parenting education aims to provide psychoeducation for parents based on character and Islamic positive habits.
\end{abstract}

\section{Keyword: Islamic Education Parenting, Hadist, Prayer Orders}

\begin{abstract}
Abstrak
Hadith perintah shalat secara tekstual dipahami sepintas terkesan menonjolkan kekerasan fisik yang tidak relevan dengan pendidikan modern. Pemahaman Hadith secara tekstual dan konstektual harus membedakan antara tujuan yang tetap dan sarana yang berubah-ubah agar Interpretasi baru atas Hadith dapat ditemukaan. Tujuan Penelitian ini adalah menjelaskan tentang konsep pendidikan Islamic Parenting dalam hadits tentang perintah sholat. Metode yang digunakan adalah library review dengan menelaah kajian kitab-kitab dan pemikiran para ulama. Berdasarkan pendidikan Islamic Parenting dapat ditelusuri spirit utama bahwa pendidikan Nabi dalam praktiknya justru dengan lemah lembut dan terbukti membawa pengaruh mendalam dalam jiwa para sahabatnya. Pendidikan Islamic Parenting bertujuan memberikan psikoedukasi bagi orangtua berdasarkan karakter dan pembiasaan positif yang Islami.
\end{abstract}

\section{Kata Kunci : Pendidikan Islamic Parenting, Hadith, Perintah Sholat}

\section{A. Pendahuluan}

Hadith perintah salat yang memerintahkan para orang tua untuk menyuruh anak-anak melaksanakan shalat yang notabene masih terbilang dini, secara tekstual dipahami sepintas terkesan menonjolkan kekerasan fisik yang tidak 
relevan dengan pendidikan modern. Meski secara tekstual Hadith berbicara tentang shalat, tetapi belakangan beberapa ulama justru mengganalisanya untuk masalah pendidikan secara umum.

Dalam konteks sosial, orang tua Muslim membolehkan memukul anaknya yang berusia 10 tahun bila tidak shalat berdasaran Hadith perintah shalat. Secara tekstual mereka berpersepsi bahwa Islam membolehkan, asal dilakukan atas nama pendidikan (li al-tarbiyyah). Di sisi lain, ada golongan minoritas yang memahami hadis sebagai bentuk perintah yang wajib dilakukan berdasarkan matan Hadith yang memakai kata perintah. Berdasarkan kaidah Ushul, asal pokok dalam perintah adalah menunjukkan hukum wajib (al-ashlu fi al-amri li al-wujub). Implikasinya, kekerasan terhadap anak menjadi hal yang wajib dilakukan.

Penelitian Murray Strauss dari New Hampshire University terhadap 1.510 anak yang mendapatkan perlakuan kasar dari orang tua menunjukkan data bahwa IQ anak yang mengalami kekerasan cenderung statis dan kesulitan untuk mengikuti jenjang pendidikan yang lebih tinggi (Finkelhor, Gelles, Hotaling, \& Strauss, 1983). Perlakuan kasar orang tua berpengaruh terhadap perilaku dan tumbuh kembang anak. Penelitian Tulane University memaparkan fakta bahwa anak usia tiga tahun yang sering mengalami kekerasan fisik dari orang tuanya akan bersikap agresif saat berusia lima tahun. Perilaku agresif akan meningkat sejalan dengan seringnya kekerasan yang ia alami. Kekerasan menjadi pengalaman traumatik bagi anak. Semakin sering mendapatkan kekerasan, maka anak akan semakin lambat perkembangan mentalnya (melindahospital, nd). Penelitian Unicef tahun 1998 juga menunjukkan data bahwa kejadian traumatik akibat kekerasan berakibat buruk bagi otak sekaligus kepribadian anak (melindahospital, nd).

Usia Tujuh tahun dan sepuluh tahun yang notabene belum mencapai baligh inilah pokok permasalahannya. Secara tekstual, dalam Hadith para orang tua diperintahkan untuk menyuruh anak-anak mengerjakan shalat pada usia tuhuh tahun dan diperintahkan untuk memukul anak-anak mereka yang meninggalkan shalat pada usia sepuluh tahun. apa pesan pokok yang hendak disampaikan Rasul? Masih relevankah Hadith ini dengan perkembangan pendidikan modern?. Artikel ini akan mengkaji pemahaman Hadith perintah salat secara tekstual dan 
konstektual berdasarkan pendapat para ulama kemudian dielaborasikan dengan pendekatan islamic parenting agar dapat diungkap pesan pokok Hadith dan relevansinya dengan semangat perkembangan zaman modern.

\section{B. Landasan Teori}

\section{Pemahaman Hadith Secara Tekstual dan Konstektual}

Hadith populer yang membolehkan memukul anak dalam mendidik shalat lima waktu secara garis besar dapat digolongkan kepada dua jalur. Pertama, riwayat Abū Dāwūd dari jalur Muhammad bin 'Isā Ibn al-Tabbā', dari Ibrāhīm bin Sa'd, dari 'Abd al-Mālik bin al-Rabī' bin Sabrah, dari ayahnya, dari kakeknya, dari Rasulullah Saw dengan redaksi murū (perintahlah) (al-Sijistān̄̄, 2009). Riwayat Abū Dāwūd dengan redaksi murū (perintahlah) juga diriwayatkan oleh Ibn al-Jarūd (Jarud, 1988), al-Tabarī (Tabari, 1994), al-Bayhaqī (Bayhaqi, 2003), dan al-Baghawī (Bahgawi, 1983). Hadith riwayat Abū Dāwūd dengan redaksi murū (perintahlah) adalah:

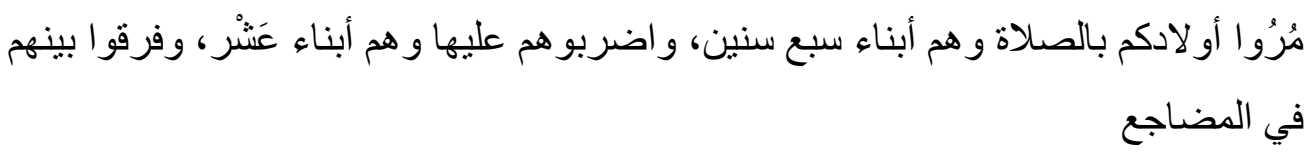

"Suruhlah anak-anak kecil kamu melakukan salat pada usia tujuh tahun, dan pukullah mereka (bila lalai) atasnya pada usia sepuluh tahun, dan pisahkanlah mereka di tempat-tempat tidur".

Kedua, riwayat al-Tirmidzī dari jalur 'Ali bin Hujr, dari Harmalah bin 'Abd al-'Azīz, dari 'Abd al-Mālik bin al-Rabī', dari al-Rabī’ bin Sabrah, dari Sabrah bin Ma‘bad, dari Rasulullah Saw dengan redaksi 'allimū (ajarilah) (Tirmidzi, 1975). Riwayat al-Tirmidzi dengan redaksi 'allimu (ajarilah) juga diriwayatkan al-Dārimī (Darimi, 2000), Ibn Khuzaymah (Khuzaymah, 2000), alTahāwī (Tahawi, 1994), al-Tabarī (Tabari, 1994), al-Hākim (Hakim, 1990), dan al-Bayhaqī (Bayhaqi, 1991). Hadith riwayat al-Tirmidzi dengan redaksi 'allim $\bar{u}$ (ajarilah) adalah:

$$
\text { علمُو ا الصبي الصلاة لسبع سنين، واضربو اه عليها لأبن عَشْر سنين ، }
$$

"Ajarkan Shalat pada anak jika berusia tujuh tahun dan pukullah jika meninggalkan shalat bila berusia sepuluh tahun". 
Konteks Hadith adalah untuk anak-anak yang belum mencapai masa baligh. al-San‘ānī menyatakan bahwa perintah memukul anak pada usia sepuluh tahun jika ia meninggalkan shalat menunjukkan bahwa anak usia sepuluh tahun sudah dibebani shalat. Hal senada disampaikan al-Khattābī, teks Hadith "jika telah sampai sepuluh tahun, maka pukullah ia" menunjukkan semakin tegasnya sanksi jika meninggalkan shalat dengan memaparkan hukum orang yang meninggalkan shalat secara sengaja (tārik al-shalāh)(Kattabi, 1932).

Berbeda dengan Ibn Rajab al-Hanbalī, menurutnya shalat belum wajib bagi anak yang belum baligh. Namun menjadi keharusan bagi orang tua memerintahkan anak mengerjakan shalat setelah menginjak usia tujuh tahun dan memukulnya jika meninggalkan shalat pada usia 10 tahun ke atas (Hanbali, 1996). Badr al-Din al-'Ayn̄̄ dan Ibn Hajar al-'Asqalānī menyatakan bahwa kata perintah tidak menunjukkan kewajiban shalat bagi anak, melainkan hanya sekadar pembelajaran (irsh $\bar{a} d$ ) dan pendidikan ( $t a^{\prime} d \bar{\imath} b$ ) yang dibebankan kepada orang tua. Sebab, anak yang dibicarakan di sini belum mencapai baligh, jadi ia bukan mukallaf (Aini, 1999).

Menurut al-Abadī, usia tujuh tahun dipilih secara eksplisit sebagai permulaan pengajaran dan pendidikan shalat anak, sebab anak telah dapat membedakan yang baik dan yang buruk (tamyizz). Sedangkan usia sepuluh tahun dipilih secara eksplisit sebagai permulaan penerapan pukulan sebab anak sudah sejengkal lagi menuju masa baligh. Semua hanyalah pembelajaran dan pendidikan shalat bagi anak (Abadi, 1415). Qawām al-Sunnah menganggap pendidikan dan pengajaran shalat dengan disertai pukulan sebelum usia baligh merupakan proses pembiasaan supaya tidak berat mengerjakan shalat di usia baligh (Qawam, 1993).

Menurut Ibn 'Allān, al-'Irāqī, dan al-Mala 'Alī al-Qārī, perintah shalat kepada anak usia tujuh tahun dan perintah memukulnya pada usia sepuluh tahun jika meninggalkan shalat adalah sekadar latihan dan pembiasaan agar anak tidak akan meninggalkan shalat ketika telah dewasa nanti (Iraqi, 2002), sebagaimana riwayat Ibn Abbas: Bangunkanlah anakmu (ajaklah anakmu) untuk shalat walau hanya satu kali sujud. Dan riwayat Abdullah bin Abbas: Perhatikanlah anak-anak kalian dalam masalah shalat, lalu biasakanlah dengan kebaikan, karena sesungguhnya kebaikan itu dengan pembiasaan (Bayhaqi, 2003). 
Menurut 'Abd al-Rahmān al-Mubarakfūrī, makna kata 'allimū al-shalāh adalah pembelajaran tata cara shalat, baik syarat maupun rukunnya kepada anak. Sedangkan makna kata al-darb adalah pukulan yang tidak menyakitkan, apalagi mencederai. Pukulan jangan dialamatkan ke wajah (Furi, nd) sebagaimana Hadith Rasul: "Apabila salah seorang di antara kalian memukul, hendaknya menghindari wajah" (Bukhari, 2005). Salih al-'Uthaymin menjelaskan maksud pukulan adalah pukulan biasa yang menghasilkan pendidikan tanpa disisipi unsur menyakiti sebagaimana Rasul memerintahkan memukul anak semata-mata demi mendidik mereka, dan bukan untuk menyakiti (SAlih, 1426).

Menurut Ibn Qayyim, pukulan untuk mendidik anak secara kuantitas tidak boleh lebih dari sepuluh kali. Ibn Qayyim menganalogkan dengan pukulan seorang suami terhadap isteri, seorang tuan kepada budak, ataupun seorang majikan kepada pegawai Jauziyah (2009). Akan tetapi sebagaian ulama menolaknya, karena memiliki spirit yang berbeda. Hukuman dalam Islam ditujukan untuk pelaku tindak kriminal, sementara anak dalam Hadith ini jelas bukan pelaku kriminal.

Yusuf al-Qardhawi mengemukakan teori bahwa dalam memahami Hadith Nabi, seseorang harus membedakan antara tujuan yang tetap dan sarana yang berubah-ubah. Pesan teks hadis sebenarnya memiliki maksud dan tujuan tertentu. Maksud dan tujuan sifatnya tetap, tidak berubah hingga kapanpun, karena itulah tujuan hakiki shareat. Sedangkan sarana dan prasarana bisa saja berubah sesuai perkembangan zaman. Konsep al-Qaradawi yang membedakan antara sarana yang berubah-ubah dan tujuan pokok Hadith harus diidentifikasi bahwa tujuan pokok dalam Hadith tidak lain adalah pendidikan secara tegas. Sedangkan sarana untuk mencapai pendidikan secara tegas merupakan praktik relevan pada waktu itu. Dengan demikian, pemukulan hanya sekadar sarana yang relevansinya dapat berubah-ubah seiring dengan perkembangan zaman (Qardawi, 2006).

Jika tujuan pokok pendidikan secara tegas dapat dicapai dengan sarana yang relevan dan mendidik selain pukulan pada masa kini, maka menerapkan hukuman selain pukulan, seperti hukuman tidak diberi uang jajan, membersihkan rumah, atau apapun dan bagaimanapun yang dapat membuat si anak jera meninggalkan shalat dengan memperhatikan indikator yang ada dari Hadith itu 
sendiri maupun dari Hadith lain. Terlepas dari beragam perspektif di atas, para ulama sepakat terhadap pesan moral Hadith bahwa tujuan utamanya adalah pembiasaan anak terhadap pelaksanaan ibadah shalat 5 waktu yang secara eksplisit diutarakan Qawām al-Sunnah, al-'Irāqī, al-Mala 'Alī al-Qari, Ibn 'Allan, dan lainnya. Praktik ibadah shalat 5 waktu diharapkan dapat mendarah daging dalam diri sejak usia dini.

Usia tujuh tahun sebagai permulaan perintah shalat anak dan sepuluh tahun sebagai permulaan penerapan pukulan terhadap anak yang enggan melaksanakan shalat. Usia tujuh tahun dinyatakan Rasul secara eksplisit bukan untuk membatasi usia permulaan pendidikan ibadah anak, akan tetapi dipilih sebagai permulaan pendidikan ibadah. Masa itu merupakan usia strategis untuk menyediakan pengetahuan kognitif tentang ibadah kepada anak. Oleh karena itu, redaksi murū (perintahlah) dan redaksi 'allimū (belajarilah) merujuk pada pengajaran orang tua tentang tata cara shalat secara teknis berdasarkan kapasitas intelektual anak. Redaksi murū (perintahlah) jika dikaitkan dengan redaksi 'allimū (belajarilah) tidak hanya memerintah anak mengerjakan shalat, melainkan harus mengajarkan shalat kepadanya dahulu sebelum memerintahkannya.

\section{Metode Penelitian}

Metode yang dipakai adalah library research, dimana peneliti menggunakan literature yang ada, kemudian mengklasifikasikannya, kemudian membandingkan antara pemikiran beberapa ulama dan madhzab dalam Pendidikan Islamic Parenting dalam Hadith Perintah Shalat. Hasilnya peneliti mengambil kesimpulan dari beberapa pemikiran kemudian mengambil kesimpulan dari literasi tersebut.

\section{Hasil dan Pembahasan}

\section{Pendidikan Islamic Parenting dalam Hadith Perintah Shalat}

Kata parenting secara bahasa diartikan sebagai kemampuan atau keterampilan yang dimiliki oleh orang tua dalam mengasuh anak. Shohib menyatakan bahwa parenting merupakan cara yang digunakan oleh orang tua untuk mengasuh anak, baik secara langsung maupun tidak langsung (Shohib, 
2001). Baumrind menyatakan parenting pada prinsipnya merupakan parental control yaitu bagaimana orang tua mengontrol, membimbing, mendampingi anak untuk melaksanakan tugas-tugas perkembangannya menuju proses pendewasaan (Bamrind, 2001).

Hal senada diungkapkan Kohn bahwa pola asuh atau pengasuhan merupakan cara orangtua berinteraksi dengan anak yang meliputi pemberian aturan, hadiah, hukuman dan pemberian perhatian, serta tanggapan orangtua terhadap setiap prilaku anak (Casmini, 2007). Sedangkan Karen menyatakan bahwa kualitas pola asuh yang baik adalah kemampuan orangtua untuk memonitor segala aktivitas anak, sehingga ketika anak dalam keadaan terpuruk orangtua mampu memberikan support dan memperlakukan anak dengan baik, sesuai dengan kondisi anaknya (Karen, 2008).

Berdasarkan beberapa definisi di atas, Islamic Parenting merupakan upaya untuk mempersiapkan generasi muda yang memiliki moral berpondasikan normanorma Islam dan membentuk generasi yang berkualitas. Konsep Islamic Parenting memandang bahwa perilaku anak di masa depan adalah cerminan dari orang tuanya dan pola pendidikan yang diterapkan dalam keluarganya. Sikap orang tua dalam membentuk karakter anak dimulai bukan saat anak tersebut lahir, melainkan dimulai sedini mungkin dengan diawali pembekalan ilmu terhadap orang tua terlebih dahulu (Suwaid, 2010).

Islamic Parenting melingkupi tata cara mendidik anak dalam tiga periode yaitu: Pertama, periode pra-konsepsi, yaitu pendidikan dimulai semenjak seseorang memilih pasangan hidupnya sampai terjadi pembuahan dalam rahim sang Ibu. Kedua, periode pre-natal, yaitu pendidikan yang diberikan orang tua ketika anak masih berada dalam kandungan. Ketiga, periode post-natal, yaitu pendidikan yang diberikan sejak anak lahir, dewasa bahkan sampai meninggal dunia yang dikenal dengan long life education. Islamic Parenting menekankan pendidikan agama sebagai dasar bagi anak menghadapi dunia.

Menurut Kohnstam, anak mempunyai sifat khusus yang perlu diperhatikan pada rentang waktu di tahap intelektual. Sifat-sifat yang mempunyai relevansi dengan hadits perintah salat adalah perhatian terhadap kehidupan praktis seharihari, rasa ingin tahu dan ingin belajar terhadap hal-hal yang membutuhkan 
bantuan guru atau orang tua (Subrata, 1984). Tidak mengherankan jika seorang ayah melatih anaknya yang masih belia menuju masjid untuk melaksanakan shalat jamaah. Padahal orang tua sadar apa yang terjadi dengan anaknya di masjid. Anak tidak fokus mengerjakan shalat, menengok ke sana ke mari, menciptakan gerakan shalat sendiri, bahkan akan bermain bersama temannya atau malah tidak mengerjakan shalat sama sekali.

Tujuan utamanya adalah pembiasaan anak-anak terhadap pelakanaan ibadah sholat yang kelak menjadi praktik kehidupan mereka. Dengan pembiasaan seperti diutarakan Qawam al-Sunnah, al-'Iraqi, al-Mala 'Ali al-Qari dan Ibn 'Allan di atas, praktik ibadah diharapkan dapat mendarah daging dalam diri karena telah terbiasa mengerjakannya sejak dini. Dalam riwayat Ibn Abbās disebutkan: Bangunkanlah anakmu untuk shalat walau hanya satu kali sujud. Dalam riwayat lain, Ibn Abbās berkata: Perhatikanlah anak-anak kalian dalam masalah shalat, lalu biasakanlah dengan kebaikan, karena sesungguhnya kebaikan itu dengan pembiasaan (Bayhaqi, 2003).

Usia tujuh tahun sebagai permulaan perintah shalat anak dan sepuluh tahun sebagai permulaan perintah penerapan pukulan terhadap anak yang enggan melaksanakan shalat, secara psikologis sesuai dengan kapasitas intelektual anak. Usia tujuh tahun dipilih sebagai permulaan pendidikan ibadah anak, karena usia itu merupakan usia strategis untuk menyediakan pengetahuan kognitif tentang ibadah kepada anak. redaksi muru (perintahlah) dan 'allimu (belajarilah) merujuk pada pengajaran orang tua tentang tata cara shalat secara teknis disertai implementasinya berdasarkan kapasitas intelektual anak.

Pada tahap intelektual, anak telah siap menerima pengetahuan kognitif dan praktik ibadah yang hendak diajarkan. usia tujuh tahun tidak bermaksud membatasi permulaan pendidikan shalat, namun pendidikan ibadah anak harus dimulai sedini mungkin sebagaimana petunjuk Rasul. Di antara riwayat fleksibilitas batasan usia adalah riwayat Mu'adz bin Abdullah al-Juhni ketika berkunjung kepada Hisyam bin Sa'ad, maka ia bertanya: "Kapankah seorang anak diperintah shalat?” Ia menjawab: Dulu ada seorang laki-laki dari kami bercerita bahwa Rasul pernah ditanya seperti itu. Beliau menjawab: "Saat anak itu mengetahui mana arah kanan dan mana kirinya, maka perintahkanlah untuk 
shalat.". Dalam riwayat lain, disebutkan bahwa Ibrahim berkata: "Mereka (para sahabat) mengajarkan anak-anak mereka shalat saat mereka sudah ganti gigi"'(Bayhaqi, 2003)

Pembiasaan ibadah sejak dini akan mengurangi perasaan berat menjalankan ibadah ketika beranjak dewasa. Dalam psikologi, kebiasaan secara signifikan mampu memotivasi anak selalu bertingkahlaku berdasarkan kebiasaan. Kebiasaan baik akan memotivasi pemeliharaan kebaikan, sebagaimana yang buruk akan memotivasi pemeliharaan keburukan. Menurut Aaron Quinn Sartain, Alvin John North, Jack Roy Strange dan Harold Martin Chapman, manusia mempunyai motivasi dalam setiap tingkah laku mereka. Kebiasaan dapat dinyatakan semacam kristalisasi motivasi yang termanifestasi dalam pola yang teratur (Sartain, 1958). Setelah motivasi memproduksi tingkah laku dan melekat kuat dalam kerangka kebiasaan, kebiasaan akan tetap berlangsung, walaupun motivasi awal telah lenyap. Kebiasaan secara otomatis menjadi motivasi otonomfungsional, yaitu motivasi mandiri yang dapat memelihara tingkah laku berdasarkan kebiasaannya.

Dalam Islam, pembentukan karakter anak menjadi tanggung jawab orang tua sebagai lingkungan yang memiliki pengaruh yang sangat besar. Diriwayatkan dari Abu Hurairah, dari Nabi Muhammad Saw, bahwasanya beliau bersabda: "Setiap anak dilahirkan dalam keadaan fitrah, maka kedua orang tuanyalah yang menjadikannya Yahudi, Nashrani, dan Majusi"(Hanbak, 1971) Pentingnya parenting yang diartikan sebagai proses menjadi orang tua dimaksudkan di sini adalah bagaimana orang tua menjalankan tugas dan tanggung jawabnya sebagai orang tua. Tugasnya tidak hanya melahirkan dan mengasuh atau membesarkan, namun yang lebih berat adalah mendidik.

Menurut Martin Davies, profesor Social Work di Universitas Of East Anglia Norwich Inggris, parenthing pada dasarnya adalah pola asuh dan pendidikan sejak anak lahir sehingga anak telah memenuhi kriteria untuk disebut sebagai pribadi yang dewasa, bukan hanya dewasa secara fisik, namun juga dewasa secara mental atau psikologis. Ratna Megawangi menjelaskan bahwa parenting merujuk pada suasana kegiatan belajar mengajar yang menekankan kehangatan bukan kearah pendidikan satu arah atau tanpa emosi. Istilah parenting 
diartikan bahwa pendidikan akan lebih memeberikan hasil maksimal dengan suasana yang ada dalam keluarga (Ratuliu, 2015).

Rudi Cahyono menyebutkan tiga prinsip dalam pengasuhan anak. Di antaranya Anak adalah subjek, bukan objek dalam pengasuhan. Anak adalah pusat dari perubahan. Meski pengasuhan bisa mengacu kepada individu, komunitas, atau masyarakat, namun peran utama dipegang orangtua dan keluarga sebagai lingkaran terdekat dari anak. Anak menjadi actor utama atas diri mereka. Artinya, anak-anak berhak meyakini dan menentukan pilihan atas perilakunya sendiri (Cahyono, 2015). Hikmah di balik lamanya sujud Nabi adalah pengenalan akan garakan-gerakan shalat untuk cucu Nabi yang masih kecil. Di sinilah tampak sekali metode lain yang dipraktikkan Nabi dalam menanamkan ajaran shalat kepada anak kecil, bukan dengan memukul atau kekerasan lain, tetapi dimulai memberikan praktik atau contoh.

Jika teori parenting diterapkan untuk memahami Hadith bolehnya memukul anak sepuluh tahun yang tidak shalat, maka tujuan hadis adalah upaya mendidik anak agar memperhatikan shalat sejak dini. Orang tua wajib sejak dini menanamkan perasaan bahwa shalat adalah sesuatu esensial dalam kehidupan seorang Muslim. Memukul hanya masalah teknis belaka untuk mencapai tujuan tersebut. Ia dapat digantikan dengan hal lain yang lebih efektif dalam mencapai tujuan.

Merujuk pada teori pendidikan kontemporer, Hadith kebolehan memukul anak dalam rangka mendidik sebenarnya mengisyaratkan konsep reward and punishment kepada anak didik. Hanya saja, yang terdapat dalam teks Hadith itu baru tentang konsep punisment. Sementara Hadith yang menunjukkan reward Nabi terdapat dalam Hadith lain dan tidak disinggung atau dikaitkan dengan Hadith hukuman dengan pukulan.

Beberapa personal mungkin terburu-buru menyimpulkan bahwa kekerasan memiliki legalitas tersendiri dalam pendidikan Islam hanya bermodalkan satu Hadith. Padahal banyak Hadith yang menunjukkan bahwa Nabi menempuh caracara penuh kelembutan dan kasih sayang dalam mendidik. Dalam riwayat 'Aisyah dikatakan: "Demi Allah, Rasulullah tidak pernah memukul dengan tangannya, baik terhadap isteri maupun terhadap pelayannya, kecuali dia berjihad di jalan 
Allah"( Nasai, 2001). Redaksi Hadith memakai kata sumpah. Artinya, Nabi tidak pernah mempraktikkan kekerasan dalam mendidik para sahabatnya, baik sahabat yang masih kecil maupun sudah dewasa.

Anas bin Mālik sahabat yang sejak kecil diserahkan ibu kandungnya untuk ikut dan dididik Nabi saat masih usia 10 tahun meriwayatkan: "Rasulullah adalah orang yang paling baik akhlaknya. Suatu hari beliau mengutusku untuk suatu keperluan. Demi Allah, aku pun berangkat. Dalam benakku, aku akan berangkat sesuai apa yang diperintahkan Nabi. Aku pun berangkat hingga akhirnya melintasi anak-anak yang sedang bermain di pasar dan bergabung dengan mereka. Tiba-tiba Nabi memegang bajuku dari belakang. Aku melihat beliau tersenyum seraya bersabda, "Wahai Unais, pergilah seperti yang aku perintahkan?" Maka aku pun salah tingkah aku menjawab, "Ya, sekarang aku berangkat wahai Rasulullah "(Muslim, 2005).

Dalam riwayat lain Anas bin Malik berkata: "Aku telah melayani Rasulullah selama sepuluh tahun, sejak saat aku masih kecil. Tidak ada bandingan kebaikan sebagaimana yang ditampakkan oleh tuanku sebagaimana aku mengalaminya sendiri. Beliau tidak pernah sekali pun berkata uff (membentak), juga tidak pernah menanyakan, "Kenapa kamu melakukan hal ini?" atau menanyakan "Kenapa kamu tidak mengerjakan hal ini?"(Basti, nd).

Riwayat di atas membuktikan bahwa Nabi tidak pernah menggunakan kekerasan dalam mendidik Anas bin Malik, sekalipun saat itu Anas masih dalam usia anak-anak. Seandainya Nabi memandang kekerasan adalah salah satu metode yang baik dan layak diapakai untuk mendidik, niscaya beliau telah mempraktikkannya kepada Anas. Akan tetapi Nabi lebih memilih cara lain yang terbukti lebih efektif membekas dalam benak para sahabatnya seperti Anas bin Malik.

\section{E. Kesimpulan}

Hadith perintah shalat yang menginformasikan boleh memukul anak saat usia sepuluh tahun sebenarnya perlu dipahami secara tekstual dan kontekstual serta sesuai perkembangan zaman. Pesan pokok Hadith adalah pendidikan pembiasaan ibadah anak. Walau secara tekstual berbau kekerasan fisik, pemukulan anak dalam Hadith hanyalah dari salah satu media yang dapat berubah 
demi mencapai tujuan pokok. Dengan penelusuran pendidikan Islamic Parenting dapat ditelusuri spirit utama bahwa pendidikan Nabi justru lebih mengutamakan sikap arif dan lemah lembut dalam mendidik para sahabat. Oleh karena itu, pendidikan Islamic Parenting dapat memberikan psikoedukasi bagi orangtua berdasarkan karakter dan pembiasaan positif yang Islami serta sesuai dengan perkembangan zaman, sehingga tidak menimbulkan masalah baru.

\section{Daftar Pustaka}

'Ayn̄̄ (al), Badr al-Dīn Mahmūd bin Ahmad. 1999. Sharh Sunan Abī Dāwud, vol. II, Riyad: Maktabat al-Rushd.

'Irāqī (al), 'Abd al-Rahmān bin al-Husayn, Tarh al-Tathrīb fì Sharh al-Taqrīb, vol. VII, Mesir: al-Tab'ah al-Misriyyah al-Qadīmah, t.th.

'Uthaymin (al), Muhammad bin Sālih. 1426. Sharh Riyādh al-Shālihīn, vol. III, Riyadh: Dār al-Wathan.

Aaron Quinn Sartain, Alvin John North, Jack Roy Strange dan Harold Martin Chapman. 1958. Psychology: Understanding Human Behaviour, New York, Toronto dan London: McGraw-Hill Book Company.

Abadī (al), Muhammad Ashraf bin Amir al-'Azim, 'Awn al-Ma 'būd Sharh Sunan $A b \bar{\imath} D \bar{a} w u d$, vol. II, Beirut: Dār al-Kutub al-'Ilmiyyah, 1415 H.

Abū Dāwud, Sulaymān bin al-Ash ‘ath al-Sijistān̄̄, Sunan Abū Dāwud, taḥqīq wa ta'līq Muḥammad Shu'aib al-Arnaūd dan Muhammad Kāmil Qurrah Balbalī, Vol. I, Saudi ‘Arabiyyah: Dār al-Risālah al-'Ilmiyyah, 1430/2009.

Baghawī (al), Al-Husayn bin Mas'ūd. 1983. Sharh al-Sunnah, vol. II, Beirut: alMaktab al-Islāmī.

Bayhāqū (al), Abū Bakar Aḥmad bin Husayn bin 'Alī Ahmad bin al-Husayn. 2003. al-Sunan al-Kubra, taḥqīq wa ta'līq Muhammad 'Abd al-Qādir 'Ațā', vol. III, Beirut: Dār al-Kutub al-'Ilmiyyah.

1991. Ma 'rifat al-Sunan wa al-Athār, vol. IV, Kairo: Jam'iyyah al-Dirāsah al-Islāmiyyah.

Bukhārī (al), Abū 'Abd Allāh Muḥammad bin Ismā'il bin al-Mughīrah. 1429/2008. Șahīh al-Bukhāri, taḥqīq wa ta'līq Muḥammad 'Abd al-Qādir al-Shaybah al-Hamd, Vol. VI, Saudi Arabiyyah: Maktabah al-Fahd alWațaniyyah athnā' al-Nasr.

Cahyono, Rudi. 2015. Daily Parenting: Menjadikan Orang Tua Pendidik yang Luar Biasa, Jakarta: Pandamedia.

Casmini. 2007. Emotional Parenting Dasar-dasar Pengasuhan Kecerdasan Emosi Anak, Yogyakarta: Nuansa Aksara.

Dārimī (al), 'Abd Allah bin 'Abd al-Rahmān. 2000. Sunan al-Dārimī, vol. II, Arab Saudi: Dār al-Mughn̄̄.

Finkelhor, D., Gelles, R. J., Hotaling, G. T., \& Strauss, M. A. 1983. The dark side of families: Current family violence research. Sage.

Hākim (al), Abu 'Abd Allāh Muhammad bin 'Abd Allāh. 1990. al-Mustadrak 'ala al-Sahihayn, vol. I, Beirut: Dār al-Kutub al-'Ilmiyyah. 
Ibn 'Allān, Muhammad bin 'Ali bin Muhammad. 2004. Dal̄̄l al-Fālihīn li Turuq Riyād al-Sālihīn, vol. III, Beirut: Dār al-Ma'rifah.

Ibn Abu Syaibah. 1405/1985. Mushannaf Ibn Abī Syaibah, vol. IV, Beirut: Muassasah al-Risālah.

Ibn al-Jārud, 'Abd Allāh bin 'Al̄̄. 1988. al-Muntaqā min al-Sunan alMusannadah, Beirut: Mu'assasāt al-Kitāb al-Thaqāfiyyah.

Ibn Hanbal, Aḥmad bin Muḥammad. 1971. Musnad al-Imām Ahmad bin Hanbal, taḥqīq wa ta 'līq Muḥammad 'Abd al-Qādir 'Ațā', Vol. XX, Beirut: Dār alKutub al-'Ilmiyyah.

Ibn Hịbān, Muḥammad bin Aḥmad Bastī, Sunan Ibnu Hibban, vol. VII, tt: Mu'assasah al-Risalah, tth.

Ibn Khuzaymah, Muhammad bin Ishāq, Sahih Ibn Khuzaymah, vol. II, Beirut: alMaktab al-Islāmī, t.th.

Ibn Rajab al-Hanbālī, 'Abd al-Rahmān bin Ahmad. 1996. Fath al-Barī Sharh Shahīh al-Bukhārī, vol. VIII, Madinah: Maktabah al-Ghurabā' alAthariyyah.

Jauziyah (al), Ibn Qayyim. 1423/2009. I'lām al-Muwaqqi 'ìn 'an Rab al-'Ālāmìn, Vol. II, Saudi Arabia: Dār al-Jawziyyah.

Karen, M. \& Claudio. 2008. Pathway to Competence: Adversity the roles of Parenting Quality and Social Support, The journal of psychology, Heldref Publication. 142 (4).

Khattābī (al), Hamd bin Muhammad. 1932. Ma 'ālim al-Sunan: Sharh al-Sunan Abi Dāwud, vol. I, Halab: al-Matba'ah al-'Ilmiyyah.

Megawangi, Ratna. 2007. Character Parenting Space, Menjadi Orang Tua Cerdas Untuk Membangkitkan Karakter Anak, Bandung: Mizan Media Utama.

Mubarakfūrī (al), Muhammad 'Abd al-Rahmān, Tuhfat al-Ahwadhī bi Sharh Jāmi ‘ al-Tirmidhī, vol. II, Beirut: Dār al-Kutub al-'Ilmiyyah, t.th.

Muslim. 1426/2005. al-Hajjāj Abū al-Ḥusain al-Qusyairi al-Naisābūrī, Șahīh Muslim, taḥqīq wa ta'līq Muhammad Fu'ād Abd al-Baqī, Vol. IV, Beirut: Dār al-Ihyā' al-Turāth al-'Arabī.

Nasā'i (al). 1421/2001. Abū 'Abd al-Raḥmān Aḥmad bin Shu'aib, Sunan alKubrā, taḥqīq Hasan Bin al-Manā'im al-Shalb̄̄, Vol. V, Beirut: Muassasah al-Risālah al-'Ilmiyyah.

Qardāwī (al), Yūsuf. 2006. Kayfa Nata'amal ma'a al-Sunnah al-Nabawiyyah, Kairo: Dār al-Shurūq.

Qārī (al), 'Alī bin Muhammad. 2002. Mirqāt al-Mafātih: Sharh Mishkāt alMasābīh, vol. II, Beirut: Dar al-Fikr.

Qawām al-Sunnah. 1993. Ismā 'il bin Muhammad, al-Targhīb wa al-Tarhīb, vol. I, Kairo: Dār al-Hadīth.

Ratuliu, Mona. 2015. Paren Think, Jakarta: Noura Books.

Shohib. 1998. Pola Asuh Orang Tua, Jakarta: Rineka Cipta.

Suryabrata, Sumardi. 1984. Psikologi Pendidikan, Jakarta: Rajawali.

Suwaid, Muhammad Nur Abdulah Hafizh. 2010. Prophetic Parenting, Yogyakarta: Pro-U Media.

Tabarī (al), Sulayman bin Ahmad. 1994. al-Mu'jam al-Kabìr, vol. VII, Kairo: Maktabah Ibn Taymiyah. 
Tahāwī (al), Ahmad bin Muhammad. 1994. Sharh Mushkil al-Āthār, vol. VI, Beirut: Mu'assasāt al-Risālah.

Tirmidzī (al), Muhammad bin 'Isā. 1975. Sunan al-Tirmidzī, vol. II, Mesir: Shikah wa Maktabah wa Matba'ah Mustafā al-Bābī al-Halabī. 